\title{
The Use Of A Digital Learning System For Developing Pedagogical Skills: Ideas For Research-Based Practice
}

\author{
Ruby Hanson, Emmanuel Kutorglo \\ University of Education, Winneba, Ghana
}

\begin{abstract}
This study involved five postgraduate teacher trainees at the University of Education (UEW), Ghana, who were on a summer programme. A Moodle Learning Management System, videos and micro teaching sessions were employed to provide and equip the teacher trainees with the needed pedagogical skills, while questionnaires, WhatsApp social media platform, and interviews were used to collect data to evaluate whether a digital learning system could provide learners with enhanced interaction modes to improve their pedagogical skills. Results indicated that the digital learning system increased student-teacher interaction, student-student interaction and equipped the trainees with requisite pedagogical skills for professional development. An identified problem was lack of stable internet connectivity which was initiated mostly by power outages at the time of this research, but could be salvaged, with improvement in power supply. Recommendations for further improvement are suggested.
\end{abstract}

\section{Introduction}

Digital communication has become an indispensable part of everyday life, and is prevalent in higher education. It has become almost imperative to incorporate emerging technologies to help learners to develop 21st Century learning skills. Digital learning coming at the back of this has changed the way people obtain knowledge and exchange information. It allows learning to take place at any time and from anywhere. Online learning is a growing digital learning mode. This mode involves the use of Information Communication Technology (ICT) tools, digital contents and the internet to present information to learners and for learning. ICT among others is used to refer generally to the amalgamation of computer networks, audio-visual, and telephone networks through a single cabling or link system.

Many studies have shown the usefulness of employing the computer in education to create interactive communication platform for permitting access to and expression of information in education $[1,2]$. With computers and their networks, so much information and opportunities are now available, such that, science laboratory activities can be performed virtually online; simulating perfectly what one will physically experience in a science laboratory. This has made it possible for scientist to try out otherwise 'dangerous' experiments in greater virtual safety compared to what Hanson [3] proposes with the adoption of microscience equipment.

In educational circles, ICT has been observed to be potent in forging collaboration, enhanced adult and self-learning, and has provided opportunities for people to learn and share information across the World Wide Web and among themselves in what is referred to in pedagogy as connectivism $[4,5]$. ICT enables teachers and learners to link other learning communities in diverse ways. It also enhances learners' motivation, links them to sources of information, and allows teachers more quality time for facilitation and reflection towards continuous professional development [6]. In a similar vein, the art or pedagogy of teaching could use ICT so that learners not only have access to student-student and student-teacher interactions for theoretical work through ICT, but also for pedagogical lessons and activities in a more connected manner.

For those living in rural areas, the Internet provides access to services that may not be available in their own communities [7]. Digital environments provide both the technology and opportunity to liberate people from limitations imposed on them by geographical locations, disability, ethnicity, gender and age. Through such environments equity in education is ensured. Learners with working schedules or locations that make it difficult to access face-to-face learning can find these digital environments useful. They can experience blended learning programmes that combine face-to-face instruction with online components. Digital technology, will in such an instance, play a key role as a supporting pedagogical tool. In digital environments, learner autonomy can be promoted as these environments provide course content and a variety of learning styles which suit individual needs [8]. Thus, the former 'all-knowing' teacher presence is not required as the teacher now serves only as a facilitator.

The main aim of integrating technology in education is to assist learners to acquire skills and knowledge through interchange, interaction, and group work, as reiterated earlier. Such integration does not mean taking one's lesson, topic or curricula and uploading it and then using the computer to teach or display the information [9]. ICT in 
education employs instructional methods such as simulations to enhance understanding of many conceptual and abstract phenomena. When used effectively, it engages learners in an exciting way so that learning becomes 'less burdensome'. It motivates and challenges learners' innate capabilities, so that knowledge construction can be based upon tested assumptions [3]. Students thus develop desired reflective, process and concept skills. ICT generally allows students the freedom to explore the wealth of knowledge online at their convenience, even if unguided. Teaching in an online environment requires a proactive paradigm shift for teachers and students alike. In this wise, designers have a responsibility to ensure successful paradigm shifts. They should consider skill requirements, rights and responsibilities of teachers and learners, as well as online conduct and etiquette, so that academic work can be carried out in a disciplined environment.

Integration of technology affords changes in pedagogy and content knowledge as teachers shift perspectives on what knowledge is valued and where the knowledge is obtained. It enables a focus on student-centred learning, with learners engaging in different tasks that are often inquiry-based rather than focused on a finite set of content points [10]. Furthermore, it empowers students and reforms their ideas about education [11], especially when they are exposed to, and encouraged to engage in solving eexamples in their own time and space. Such integration could be made for full online learning or hybrid (blended) learning.

Blended learning is an amalgamation of the traditional face-to-face learning and 'full' online learning. Blended learning acknowledges the teacher-presence as it would in the traditional classroom. Yet, it accommodates the presence of a teacher as a facilitator, as expected in online learning. During face-to-face sessions, some topics might warrant that the teacher takes the stage to direct the pace of learning as he or she provides what students need to know. Though not the best, teachercentred pedagogies might be adopted to make the achievement of curriculum objectives a reality. In a teacher-centred environment, a teacher equipped with requisite pedagogical skills is able to create and sustain an interactive classroom by acquiring a few basic ICT skills. Without coercion such a teacher is able to integrate e-learning in his lessons. It is for this reason and many more that this study sought to find out how ICT could be harnessed in the field of education, by particularly enabling prospective graduate teachers to acquire diverse pedagogical skills within a limited time frame of study.

E-examples [12] are developed by teachers to give students opportunities to practise and learn in active ways, through the use of internet so as to test their knowledge and thereby increase cognition. E- examples, like e-mail or e-commerce, are examples of concepts, principles and learning ideas transmitted over the internet. Such examples of exercises allow for self-studies during and outside class as well. These e-exercises or e-examples can support active learning over a wide range as they expose students to variety of tests and learning formats. More interestingly, learners get immediate feedback. For teachers or facilitators, feedback is given in real or delayed time as desired. The maintenance cycle is short and distribution is easy. For teacher training institutions, e-teaching and learning appears to be an innovative and exciting way to change the face of teaching and learning.

The University of Education, Winneba, UEW, which is a teacher training institution, has moved the majority of its lessons onto the virtual learning environment via a Moodle platform so that lessons are now carried out in a hybrid fashion. Students go online to do their own learning and interact with their teachers via the Moodle platform and occasionally come to class for face-to-face sessions. The purpose of moving classes online was to cater for its large student-base; particularly its summer school and distance education students. For purposes of clarity, the 'summer school' or 'distance' learners are those students who attend school on Campus outside the usual regular school sessions, while the 'distance' learners are those students who are 'off-campus' learners and visit their lecturers on campus once a while (during weekends) for face-to-face sessions. The introduction of the hybrid lessons on Moodle was also intended to enhance student-centred activities, the application of technology, and to provide support to students on and off campus basically in their acquisition of content knowledge and theoretical pedagogical concepts. A critical analysis of the hybrid online courses indicated that undergraduate teacher trainees or prospective teachers in UEW did not benefit from the acquisition of practical pedagogical skills via the online course. There were no embedded videos or opportunities in course descriptions for learners to perform or study virtual pedagogical teaching skills so that they could get acquainted with diverse teaching strategies and their effects. Thus, it was important after this analysis to find ways of incorporating online courses that could cater for deficiencies in teaching practice and the subsequent acquisition of state-of-the-art pedagogical skills in a contemporary world.

Pedagogy is the science of organising, delivering and managing educational instructional content to learners [13]. In order to execute effective pedagogical skills in one's class as an initial or beginning teacher, one must be exposed to existing or possible practices in diverse environments. Based upon such an exposure, teachers imbibe such skills for practice and make renditions of them, even when they cannot create nouvelle pedagogies of their own. 
Best teaching practices truly depend on one's own teaching pedagogies and acumen; thus, 'good' teachers are those who are able to use different teaching pedagogies to teach different categories of learners. This is what UEW strives to inculcate into its teacher trainees or initial teachers. More importantly, such a 'good' teacher is able to connect his acquired subject/discipline knowledge, available resources, students' prior knowledge and new content to be learned smoothly and effectively. Thus, to create such a 'good' teacher, a prospective teacher under training for the teaching profession must be exposed to good class management, how to manage other everyday classroom routines effectively, and other issues like the inclusion of equity and inclusivity, as well as the pros and cons of diverse pedagogies like the teacher-centred, learner-centred, learning-centred and new pedagogies that could arise. Through these and the use of technology, effective pedagogical skills would be cultivated by teacher trainees (herein also referred to as prospective teachers) [14].

\section{Rationale}

A few studies have looked at how to integrate ICT into various disciplines to enhance economic benefits [15]. Others have assessed how to enhance conception through e-lab activities [16], while a handful of researchers have studied how to use ICT to improve academic achievement [17]. Some researchers have further assessed the development of ICT into the hybrid mode for innovative ways of teaching [3]. Part of the rationale behind this current study was to address the non-integration of the acquisition of pedagogical skills with ease in online courses and to see if participants who enroll on such online-integrated pedagogical practice classes could maximise their study and practice time through an online course. That is, it was also to address time constraints with practicum sessions, allow for the review of the entire postgraduate sandwich course content for GDSc 516, and make students have the convenience of working at home, as well as initiate independence in solving problems. It further sought to explore, design and evaluate the Moodle platform as a support tool for graduate sandwich students to improve on their pedagogical skills in the face of constraints in time and space.

Sandwich students are those who enrol in courses during the summer holidays, and outside the regular school session. This study was premised on the fact that collaborating and sharing experiences is important for professional development. Learning to teach, reflecting on one's own performance as well as that of others, and discussing them dispassionately, could enhance personal professional development and one's growth in their acquisition of pedagogical skills. Thus, synchronous and asynchronous modes of presenting information to learners were adopted in the hybrid course that was developed.

\subsection{Objectives}

1. To create a work environment on a digital learning platform for postgraduate teacher trainees who were pursuing a pedagogy programme.

2. To research into the prospects that the integration of ICT could offer the graduate learners.

3. To determine the extent to which the innovative Moodle platform could affect the teacher trainees' principles and practice of teaching and assessment? 4. To determine the impact of the integrated ICT on students' pedagogical skills development.

\subsection{Research questions}

1. How would the integration of ICT as a support tool act as a digital learning platform that would enhance the pedagogical skills of graduate teacher trainees?

2. What professional development would the integration of ICT offer the adult graduate pedagogy learners?

3. To what extent would the innovative tool (digital Moodle learning platform) improve on the trainees' principles and practice of teaching and assessment? 4. What would be the impact of the integrated ICT on students' pedagogical skills development?

\subsection{Working hypothesis}

Open software is cheap, readily available, and flexible for self-tutoring in all environments. The model for designing the integration of ICT into the pedagogy course titled GDSc 516 (Principles and Practice of Teaching and Assessment of science at the Junior High School) was simple and sequenced. It allowed the designers to construct their e-content on an appropriate Learning Management System (LMS) to include resources and activities. The provision of academic and technical help was made a core need for each lesson. The Moodle platform was the researchers' choice of LMS as it was easy to use and could be easily accessed online. Besides the said, the Analyse, Design, Develop, Implement and Evaluate (ADDIE) instructional design for building instructional models and course content was employed [18].

\section{Methodology}

The courseware had to accommodate all the required components for effective teacher training the cognitive, professional, and social aspects so the courseware was mapped against these components. It 
was also to develop innovative, quality, interactive and engaging learning platforms that are based on national teaching standards, and to strengthen the teaching and learning process so as to produce holistic balanced graduates. To begin with, course manuals were analysed and developed (using the ADDIE model) as a pre-requisite to building the econtent/ lesson. The analysis phase of the integration of ICT to teach the acquisition of pedagogical skills was carried out the year before its current integration. Total available hours for the e-content were calculated and apportioned over teacher usagetime, students' expected usage-time, and collaborative activity time. This was to ensure that activities would be interactive as expected and not overloaded. Some of the activities that were embedded into the online courseware were threaded discussions in a form similar to a traditional classroom: chats, teacher lectures, videos, and reflective journals.

Lecture notes were also developed for the lessons. Web links and e-activities were embedded within the lessons and notes. Some of these were synchronous while others were asynchronous. Within all these activities, Gagne's nine events of instruction were followed to ensure that students' attention would be gained: they would be clearly informed about the objectives, present adequate stimulus to whet their appetite to read more or engage in the designed activities and above all enhance retention [19]. These nine events or principles were developed by Gagne, to enable teachers to present their lessons in a systematic and engaging manner. An in-built system recorded how often students visited the site. Activities that they turned in were assessed within the shortest possible time with comments, and posted through online back to them for improvement and encouragement. Through this iterative process the course content, instructional materials, and student learning were assessed by illuminative evaluation $[18,20]$.

After building the courseware a discussion session on how to interact with the website was organised for the five students before they began using the courseware. They were taught how to log on to the website, and edit their profile which was a requirement, upload/download images, videos and word documents and what the names of the various icons were that they were to use or engage with. These were necessary for the practical aspect of their course, where they were expected to make and upload short videos on the introduction, development and concluding parts of lessons and reflect on them. The students were expected to exchange videos of their personal teaching strategies, narrate innovations that were embedded and critique each other's videos; stating their observed strengths and weaknesses. Some of the specific activities and tools embedded in the courseware required the use of skype, videos, chats, or a reflective journal and WhatsApp.

Data obtained through open questionnaires and interviews from students was analysed descriptively into experiential themes in order to highlight the strengths and weaknesses of the integrated pedagogical skills that are to be acquired for future adjustments. Students' responses that bore apparently similar ideas were put together under a theme that bore the common idea. This was done for all the obtained responses.

\section{Results}

The main aim of this study was to assess the potential of ICT in developing pedagogical skills and to present a framework for online development of practical teaching skills for professional development [20]. It was also to find out if the new learning environment would impact positively on the students' acquisition of the required principles and practice of teaching through the blended online course. Questionnaire, informal observations and informal classroom discussions with the students indicated that there were a few misgivings about the new learning e-environment as learners were more used to the traditional face-to-face mode of tuition. Two of them though had training in the use of computer for accessing information for academic work. Nonetheless, they did not make use of what they learned to search for course-related literature. None of the participants had any idea about learning management systems (LMS) though their institution had several undergraduate and a few graduate courses online. Thus, the LMS that had been adopted by UEW, the Moodle, was introduced to the students as the platform on which some of their course content would was built on.

Table 1 shows some of the observations that students made and reported on in their answers to questionnaire items

Table 1. Students' observations on the use of the Moodle platform in learning

\begin{tabular}{lll}
\hline & Students' positive opinions & Students' challenges \\
\hline 1. & Increased engagement with course content & Meeting timelines \\
2. & Exposure to variety of learning materials & Inadequate ICT skills \\
3. & ICT competence enhanced & Interruption in internet supply \\
4. & Vivid images increased conception & No challenge identified \\
5. & Collaboration was enhanced & No challenge identified \\
6. & Communication skills improved & No challenge identified \\
7. & Exposure to different pedagogical skills & No challenge identified \\
8. & Research skills enhanced & No challenge identified \\
9 & Enhanced reflection & No challenge identified \\
10. & Enhanced cognition & No challenge identified \\
\hline
\end{tabular}

From Table 1, it can be seen that students mostly provided positive feedback on their use of ICT as a tool to enhance their pedagogical skills. The positive opinions outweighed their challenges. However, one challenge that was beyond their control and that of the tutors was interruption in internet supply due to 
power failure. It could have had an impact on their submission of assignments with timelines. Though one of the students was pessimistic about the success of the teaching and learning electronic platform (Moodle) for the course of study initially, he later came to appreciate its relevance in how it fostered collaboration and provided real time learning in one's own space and time at the end of the study. He was initially sceptical about how they could learn to develop pedagogical skills by watching other people teach in videos. He was familiar though with YouTube. These students expressed more positive and less sceptical views when questions similar to the questionnaire were posed. Two other students indicated that the e-learning mode helped them in acquiring more skills in the use of technology, while the remaining two were non-committal. One of the two non-committal students had lessons that were a mismatch between his philosophy and attested pedagogical skills. He clearly had difficulty in translating his prepared lessons into reality either in online video demonstrative practice or face-to-face practice. He had never had the chance to practice any teaching skills at all before enrolling on the course, he said. This might have accounted for his initial grave challenges. All the students, including the one who had initial grave challenges, admitted in an interview at the end of the course, with excitement, the fact that the e-learning platform had actually given them the opportunity to pursue their education in a less constrained environment. Their perspectives, as obtained from the interview are given below.

1. The digital platform created an environment free from constraints as iterated by Yang and Yenb [17] in a similar research.

2. Students intimated that the study materials were clear and concise [3].

3. Students had flexible work times; deadlines were met in accordance with the online schedule as there was a time count attached to tasks for tasks to be handed in. Beyond that time, the submission window would close so that no late submissions could be posted.

4. Students experience an amount of independence in their study and ownership of the course, as they also made vast contributions to daily activities and interacted adequately with the Moodle platform.

5 . There was a sense of familiarity and easy access to the lecturer [11].

6. There was immediate response to challenges at all times

7. Lessons were more student-centred rather than teacher-centred [10].

8. They experienced a provision of diverse and rich experience [16].

9. Real time discussions were experienced without constraint [2].
10. Real time presentation of teaching skills was made possible without physically being present in class.

The above thematic deductions from students' feedback on the innovative way of helping them to acquire pedagogical skills in a more contemporary way demonstrate some of the advantages that the students gained from their engagement with the Moodle platform.

Further opinions from the interview sessions about the e-learning platform were:

1. It increased creativity.

2. It helped to incorporate new teaching strategies which could easily be analysed and altered with ease, if found to be inappropriate.

3. It gave a sense of ownership and increased their competence.

4. It also provided exposure to alternative assessments and presentation modes.

5. It increased the acquisition and demonstration of in-depth technological pedagogical skills.

6. In all, their expectations were largely met.

The few problems encountered by the participants were pedagogical and technical issues and not so much a content issue. That is, they displayed difficulty with pedagogical skills required for their introduction and closure of lessons and experienced a few technical hitches on the smooth and regular provision of internet by their internet service providers. They did not report on any technical challenges with their laptops and computers. One student was observed to have grave problems with the introduction of his lessons and employed inappropriate teaching strategies for most of his lessons when the practice teaching began. This student who had mismatched lessons and professed pedagogical skills advanced in his use of technology, and learned how to introduce, develop and close his lessons towards the end of the study period, through practice and watching other colleagues do so appropriately and innovatively online.

\section{Discussion}

This section unravels the benefits that the participants gained from assessing pedagogical models and skills online, and integrating them into their own lesson and assignments. It also discusses the possibilities of how prospective teachers who engaged in this study will carry these acquired technological pedagogical skills on into the future; demonstrating the translation and extension of learning. From the data gathered, it was evident that the principles and practices of teaching and learning could be developed and studied as an online course through proper needs assessment and design. Analysed responses from the questionnaires 
indicated that teachers could purposefully produce videos of some of their own best teaching practices and make students watch them online in class so that they become aware of different teaching styles and best pedagogical practices. More importantly, videos of other colleague prospective teachers who have exhibited excellent teaching and management skills as well as those that had weaknesses could be analysed as projects by prospective teachers, so that they reflect on the diverse presentations and build their own best practical initial pedagogical skills.

In this current study, not only did the graduate students learn about engaging with an online platform, but also learned how to integrate technology into their lessons on Moodle or elearning platforms to facilitate the acquisition of needed pedagogical skills for their teaching careers. The platform availed an environment that students successfully engaged in online discussions about diverse methods of teaching, students' different learning styles, the uniqueness of each learning style, different teaching styles that could cater for such differences, equity and inclusivity, classroom management, assessment and many more as discussions were held through fora, chats, WhatsApp, sms and emails. Through the reflective online journals, the students could reflective on the strengths and weaknesses of the three variables of teaching and learning- the teacher, the student and resources or equipment and how to manage them for best results. From their own submissions in the interview sessions, the more they reflected on these key factors, the more they tended to understand the various characteristics of each of these and how they interacted intricately.

In order to ensure that pedagogical skills were gained in the practicum or practical sessions, one session for each student was thoroughly critiqued through analytical and reflective face-to-face sessions. After that each of the five students had to prepare and present three (5-minute) sessions of introductions to lessons, three (10-minute) sessions of lesson development and three (5-minute) concluding sessions for given topics. Furthermore, each student had to prepare two (30-minute) full lessons. In the full lessons, objectives were well written and achievable. Good instructional skills were developed, as observed from recorded videos. The display of appropriate instructional and communication skills from the videos showed the extent of professional development and the acquisition of these skills by the students. The researchers' assessments of these professional developments were corroborated by personal reflections and reflective comments from students. These interactive activities to assess the impact of teaching pedagogy through blended learning were mostly done online as students were more comfortable accessing it this way.
During the face-to-face sessions, the researchers commented on important skills that required improvement by each of the students. The digital platform allowed for many more presentations of lessons and acquisition of skills for professional development than would otherwise have been attained through face-to-face or on-presence interactions only. This observation augments what Yang and Yenb [17] also found in a study about students' perspectives of the use of e-learning in higher education, that more time was made available for discussions because students were able to execute their online tasks with ease and in relatively shorter times. A similar observation was made by Hanson [3] when micro chemistry activities were integrated into e-learning. Students in that study carried out more activities than they would have in the traditional mode, and therefore made higher cognitive gains. She noted that instructional support was necessary for managing student presentations and experimental reports which was doubled, as compared to the traditional mode. In the same vein, teacher trainees would require maximum support if pedagogical skills are to be learned and practised through virtual modes for such similar overt gains. This would eventually help them to develop professionally faster, as they sharpen their technological, content and pedagogical skills online. The students intimated in their interview sessions that the integrated pedagogical course and ICT in general presented many positive prospects for enhanced learning, class management and assessment. Not only did they acquire the desired pedagogical skills but had gained incidental learning and transferrable skills for lifelong learning. They emphasised that they had personally acquired skills to integrate ICT into their science teaching at the lower secondary level (junior high school), besides content knowledge. In addition, they acquired skills for academic writing, presentation, communication and collaboration. Other incidental skills that they stated they had developed were writing, editorial, video making, and photography skills. Students' opinions about the integrated pedagogical programme proved to be largely positive. According to Dikkers [10] the intersection of online and face-toface sessions in teacher training programmes could lead to professional development.

Students' responses to questionnaire and their opinions were found to be in line with what Hanson and Nsiah Asante [11] discovered when students' views were gathered about the integration of ICT into lessons. They attested to the benefits of dynamic visualisation, which is congruent with Herga's [2] study results. Integrating teaching and learning with technology draws learners' attention to important requirements in classroom lesson preparation and teaching, and motivates them to greater heights, as their sense of curiosity spurs them on. They added 
that seeing their own recorded online teaching practice and demonstration of pedagogical skills enabled them to become more aware of their strengths and weaknesses. It enabled them to reflect on their actions better, which eventually led to the acquisition of better teaching practices. This activity helped them to develop their teaching skills continuously and professionally as their responses helped to improve the small learning group's engagements.

In their theory classes, the search for one concept, idea or terminology about literature related to the practices of teaching and learning, led them to use the computer regularly from one search page to another and so a lot of incidental learning was acquired, as opposed to what would ordinarily have been acquired without online technologies. The students learned to collaborate as they sought for and compared ideas through student-student interactive reflections.

One other important gain that was made in this study, but was subtle, was the vast volume of content, hands-on and minds-on, and pedagogical practice work that was made possible within the regular teaching period in the semester. This was made possible because students had to prepare videos of their teaching acumen out of class, share the videos and discuss them before coming to class for a whole-class discussion on their teaching practices and skills. Evidence of having engaged in such practices were assessed before the whole class discussions. This gave students the opportunity to work on their videos again for improvement and incorporate suggestions and other feedback from their colleagues before final presentation in a face-toface class. This meant that students had more practice and time for discussion for professional development, in addition to the regular sessions indicated on their departmental timetable. Very little of the regular tuition hours were used in preparing for students' live practice teaching. Besides, the preparatory periods that were needed for the changeover (transition) of one presenter of a lesson to the other became a thing of the past as the already captured video lessons were shown on a screen for discussion, critiquing and feedback without waste of time. In other words, the transition between one presentation of a student's lesson and the other occurred smoothly as they had all been practised and videoed out of the regular class session.

Altogether, students were able to gain learning skills such as video making critiquing, analysing, constructing, processing of information, the use of the computer for literary works and lifelong skills such as collaboration, tolerance, honesty and respect for one another. These are some of the very important skills that are required for successful continuous professional development.

\section{Conclusion}

Findings from obtained data suggests that the use of digital educational technology improved among the researchers and students alike. The design focused on engaging students with each other, the content, the instructors, pedagogical skill practice and acquisition in a nouvelle way. The researchers, who already had ICT experience, improved on their expertise in designing and developing the e-course using instructional design principles. Knowledge in andragogy was an added benefit gained by the researchers, so that the learning needs of working adult category of learners could be provided for by them in their future teaching careers. The researchers' illuminative evaluation skills also improved as they worked with the students, observed them and assessed the development, use and unobtrusive impact of an e-course tool within its operational milieu.

The integration of ICT as a learning support tool enhanced the students' learning of computer skills, the course content, as well as pedagogical skills. It was clear by the end of the study session that almost all the students had developed professional teaching skills, since they learned many ethical values of professional teachers that they were hitherto not aware of. To a large extent, the videos that they made and watched in class improved their personal and group practical skills. The students furthermore developed research skills and better conceptual models of many pedagogical skills which helped to improve their technological pedagogical content knowledge for professional growth. The dedication of the researchers was one important factor that saw the completion of this study to the end. It could therefore be concluded that the integration of ICT into teacher training courses, such as GDSc 516, to enable the development of pedagogical skills for professional growth is feasible and most beneficial as it saves teaching time and allows for more practice than could otherwise have been possible in a traditional face-to-face class. Besides, it enables prospective teachers under training to develop several learning skills for continuous professional development.

\section{References}

[1] J. R. Hartley, "Learning from computer-based learning in science," Studies in Science Education, vol. 15 , no. 1 , pp. 55-76, 1988.

[2] N. R. Herga, "Virtual laboratory in the role of dynamic visualisation for better understanding of chemistry in primary school," Eurasia Journal of Mathematics, Science \& Technology Education, vol. 12, no. 3, pp. 593-608, 2016. 
[3] R. Hanson, "The impact and challenges of integrating micro chemistry experiments into elearning," International Journal for CrossDisciplinary Subjects in Education, vol. Special Issue 4, no. 1, pp. 1884-1892, 2014.

[4] J. Rowley and R. Hartley, Organising knowledge: An introduction to managing access to information, Burlington, VT, USA: Ashgate Publishing Limited, 2008.

[5] G. Salmon, E-moderating: The key to teaching and learning online, London: Kagan Paga, 2002.

[6] M. D. Roblyer, J. Edwards and M. A. Havrilule, Integrating educational technology into teaching, 4th ed., Upper saddle River, N J. USA: Prentice hall, 2004.

[7] J. Nsiah-Asante and R. Hanson, "ICT in distance education," in International Teacher Education Conference (ITEC 2017), Harvard University, Boston, Massachussetts, 2017.

[8] S. Yang, "Context aware ubiquitos learning environment for peer to peer collaborative learning," Educational Technology and Society, vol. 9, no. 1, pp. 188-201, 2006.

[9] Q. Wang and H. L. Woo, "Systematic planning for ICT integration in topic learning," Educational Technology and Society, vol. 10, no. 1, pp. 148-156, 2007.

[10] A. G. Dikkers, "The intersection of online and face-to-face teaching: Implications for virtual schoolteacher practice and professional development," Journal of Research on Technology in Education, vol. 47, no. 3, pp. 139-156, 2015.

[11] R. Hanson and J. Nsiah Asante, "An exploration of experiences in using the hybrid Moodle approach in the delivery and learning situations at the University of Education, Winneba, Ghana," Journal of Education and Practice, vol. 5, no. 12, pp. 18-23, 2014.

[12] Houghton Mifflin Company, The new dictionary of cultural literacy, NY, USA: Mifflin Company, 2005.

[13] B. N. Ireri, E. I. Omwenga, R. Oboko and R. Wario, "Developing pedagogical skills for teachers: A learner-centred approach for technology supported instructions," in Handbook of research on learner centered pedagogy in teacher education and professional development, J. Keengwe and G.
Onchwari, Eds., North Dakota, IGI Global Publishers, 2017, pp. 128-144.

[14] M. A. Amusan, "Cultivating effective pedagogical skills in in-service teachers: The role of some teacher variables," Journal of the International Society for Teacher Education, vol. 20, no. 1, pp. 8389, 2016.

[15] A. Matei and C. Vrabie, "E-learning platforms supporting the educational effectiveness of distance learning programme: A comparative study in administrative science," Procedis-social and Behavioural Sciences, pp. 526-530, 2013.

[16] R. Hanson, V. Antwi and G. Ayim, "The potential of integrating ICT into the teaching and learning of chemical bonds in senior high schools in Ghana- A case study," International Journal of Scientific Research in Science and Technology, vol. 3, no. 3, pp. 198-210, 3017.

[17] J.-Y. Yang and Y.-C. Yenb, "College students' perspectives of E-learning system use in high education," Asian Journal of Education and Training, vol. 2, no. 2, pp. 53-62, 2016.

[18] R. M. Branch, Instructional design: The ADDIE model, New York: Springer, 2009.

[19] R. Gagne, L. Briggs and W. Wagner, Principles of instructional design, 4th ed., Fort Worth, TX: HBJ College Publishers, 1992.

[20] D. L. Kirkpatrick, Evaluating training programs: The four levels, San Francisco: Berret-Koehler, 1994.

Appendix A: Student questionnaire

Your responses to this questionnaire are to help us to improve on the SCB 516 course for teaching and learning integrated science in Junior high schools.

1.Did you have any prior training in accessing the computer?

If yes, were you able to use that knowledge to access required literature for this course and perhaps other courses?

2. Have you been trained in the use of Moodle to learn?

If yes, for how long? 
3. Which of the following aspects did you get training in?
a. Basic technological skill
b. Online ethics and responsibilities
c. Interpretation of Moodle icons and their uses
$\mathrm{d}$. The meaning of online learning environment
e. The processes of online learning
4. How many courses were taught using the online platform? How many did you get feedback from?
5. Which of the following features were used?
a. Chat room
b. Forum
c. Quiz
d. Reflective journal
e. Wikis
6. State two advantages of the Moodle.
7. State two disadvantages of the Moodle
8.
a) Did you develop any pedagogical skills?
b) Were your expectations met?
c) Write down any suggestions or comments to improve the Moodle platform.

Appendix B: Interview questions

1. What are some of the gains that you assume to have made with the integration of learning pedagogical skills on this course?

2. Did the integrated ICT affect your engagement with the course content and particularly development of pedagogical skills?

3. How did it influence your interaction with your colleague and the course instructors?

4. Did you encounter any unpleasant challenges?

5. Were your expectations about the helpfulness of the new learning approach and acquisition of skills met?

6. What comments can you make on the improvement of the course? 